\title{
Spectrum of Bladder Cancer Patients Morbidity and Mortality in a Tertiary Hospital of Northwestern Nigeria: A 7-Year Review
}

\author{
Abubakar Sadiq Muhammad*, Abdullahi Khalid \\ Urology Unit, Department of Surgery, Usmanu Danfodiyo University Teaching Hospital, Sokoto, Nigeria \\ Email: *asmgusau@gmail.com
}

How to cite this paper: Muhammad, A.S. and Khalid, A. (2021) Spectrum of Bladder Cancer Patients Morbidity and Mortality in a Tertiary Hospital of Northwestern Nigeria: A 7-Year Review. Open Journal of Urology, $11,36-44$.

https://doi.org/10.4236/oju.2021.112005

Received: December 12, 2020

Accepted: February 17, 2021

Published: February 20, 2021

Copyright $\odot 2021$ by author(s) and Scientific Research Publishing Inc. This work is licensed under the Creative Commons Attribution International License (CC BY 4.0).

http://creativecommons.org/licenses/by/4.0/

\begin{abstract}
Background: Bladder cancer is a common cause of morbidity and mortality in our institution due to the late presentation. Morbidity is defined as a development of complications that may lead to mortality. Uraemia is a common presentation that constitutes a management challenge in our patients. We study the spectrum of morbidity and mortality in bladder cancer patients in our institution. Materials and Methods: This is a retrospective study of patients with clinical, radiological, cytological and or histological features of bladder cancer that had a morbidity and or mortality managed at Usmanu Danfodiyo University Teaching Hospital Sokoto from January 2011 to December, 2017. Data were retrieved from patients' case notes via a proforma and analyzed using SPSS 20.0 version for windows. The results were presented in number percent, tables and chart. Results: There were morbidity and or mortality in 234 bladder cancer patients within the study period with a mean age of $48.4 \pm 14.1$ years and a range of $3-106$ years. There were 219 males (91.5\%) and 20 females (8.5\%) with a male to female ratio of 11:1. There were haematuria and lower urinary tract symptoms (LUTS) in 230 patients $(98.3 \%)$. There were necroturia \pm weight loss and anorexia in 126 patients (53.8\%). There was urinary tract infection (UTI) in 75 patients (32.1\%), anaemia in 131 patients $(56.0 \%)$ and uraemia in 161 patients (68.8\%). Mortality was recorded in 84 patients (35.9\%) which was due to uraemia in 52 patients (22.2\%), urosepsis in 22 patients $(9.4 \%)$ and anaemia in 8 patients (3.4\%), intestinal obstruction and blood transfusion reaction in 1 patient each (0.4\%). Conclusion: Anaemia, urosepsis and uraemia are the most common causes of morbidity and or mortality in bladder tumour patients in Sokoto. This poses great diagnostic and therapeutic dilemma to the urologist, patients and their relatives.
\end{abstract}




\section{Keywords}

Bladder Cancer, Morbidity, Mortality, Urosepsis, Uraemia, Anaemia

\section{Introduction}

Bladder cancer is the $10^{\text {th }}$ common cancer worldwide. It is associated with occupational and environmental factors such as cigarette smoking, chemicals and schistosomiasis [1]. The commonest histological type is transitional cell carcinoma accounting for $95 \%$ - 97\% worldwide [2]. In Africa, transitional cell carcinoma accounts for $60 \%-70 \%$ while squamous cell carcinoma accounts for $30 \%-40 \%$ of cases [2] [3]. The 5-year survival rate in patients with metastatic disease is $5 \%$. In Sokoto North-western Nigeria, bladder cancer is the second most common cancer in men [4] with the commonest histological subtype being squamous cell carcinoma in $65 \%$ of the patients [5]. This is due to the endemicity of schistosomiasis in our environment [3] [5]. Patients usually present late with manifestations of loco-regional spread. In our clinical setting, patients present with haematuria, necroturia, weight loss, anorexia, anaemia, urinary tract infection and uraemia [6] [7]. At times, patients develop urosepsis, gross haematuria or uraemia which if unaddressed promptly may lead to mortality [7].

The associated morbidity seen in bladder cancer patients can result into mortality and constitutes a significant challenge to these patients, their caregivers and the attending urologist. This is because in addition to the bladder cancer burden, patients with anaemia could develop anaemic cardiac failure. Those with uraemia may require regular dialysis. While others with urosepsis may progress into multiple organ dysfunction or failure. The consequences of these include prolonged hospital stay and increased financial cost of treatment on patients and caregivers who are already exhausted financially even prior to presentation. Also, the degree of severity of the morbidities can impact negatively on these patients performance status which is a key consideration in the available options of their treatment. The mortality of these predominantly young cohort of patients in their very active productive age and who are mostly farmers and the family's breadwinners serve as a big setback and disruption to the family economic set up. Therefore, there is a need to study these important variables among bladder cancer patients. These pose great challenges to the emergent treatment and cystoscopy for confirmation of the diagnosis. There is no previous study done in our environment to assess these morbidities and mortality of bladder cancer.

The objective of this study is to assess morbidity and mortality of bladder cancer patients in our environment.

\section{Methods}

This is a retrospective study of patients with clinical, radiological, cytological and or histological features of bladder cancer that had a morbidity and or mortality 
managed at Usmanu Danfodiyo University Teaching Hospital, Sokoto, from January 2011 to December, 2017. Data was retrieved from patients' case notes into a proforma and analyzed using SPSS 20.0 version for windows. The data included socio-demographic parameters, clinical presentation, complications, examination findings, morbidity, mortality, ultrasound scan findings, laboratory investigations findings, cystoscopy findings, histological findings. Laboratory investigations findings included full blood count, serum electrolyte, urea/creatinine, urine microscopy, urine cytology and urinalysis. The bladder cancer patients included were those with documentation of morbidities such as anaemia, uraemia, urosepsis, and fistula or mortality with complete record as per the design proforma. Patients without documentation of morbidities or mortality as above or incomplete or missing records were excluded from this study. The results were presented in number percent, tables and chart.

\section{Results}

There were 234 patients with morbidity and or mortality from bladder cancer with a mean age of $48.4 \pm 14.1$ years. Other details of the socio-demographic characteristics of the patients' are shown in Table 1 below.

Haematuria and lower urinary tract symptoms were the most common presentations which were found in 230 patients (98.3\%) each. Other presentations are shown in Table 2 below.

The risk factors for bladder cancer found in the patients were schistosomiasis in 160 patients $(68.4 \%)$, smoking in 5 patients $(2.1 \%)$ and the both risks in 20 patients (8.5\%). Bladder mass is a feature of advanced disease. The rate of detection of bladder mass by various methods is shown in Figure 1.

Table 1. Socio-demographic characteristics of the patients with bladder cancer.

\begin{tabular}{|c|c|c|}
\hline $\begin{array}{l}\text { Socio-demographic } \\
\text { variable }\end{array}$ & $\begin{array}{c}\text { mean } \pm S D / \text { number of patients }(\%) \\
\qquad n=234\end{array}$ & Remarks \\
\hline Mean age & $48.4 \pm 14.1$ years & \\
\hline Age range & 3 - 106 years & \\
\hline \multicolumn{3}{|l|}{ Sex distribution } \\
\hline Male & $219(91.5 \%)$ & \\
\hline Female & $20(8.5 \%)$ & \\
\hline $\mathrm{M}: \mathrm{F}$ & $11: 1$ & Farming was the \\
\hline Occupation & & commonest occupation \\
\hline Farmers & $145(62.0 \%)$ & and these patients had \\
\hline Civil servant & $29(12.4 \%)$ & schistosomiasis in the \\
\hline Business man & $28(12.0 \%)$ & childhood which was \\
\hline House wife & $18(7.7 \%)$ & poorly treated \\
\hline Student & $6(2.6 \%)$ & \\
\hline Driver & $4(1.7 \%)$ & \\
\hline Clergyman & $2(0.8 \%)$ & \\
\hline Butcher & $1(0.4 \%)$ & \\
\hline Mechanic & $1(0.4 \%)$ & \\
\hline
\end{tabular}


Table 2. Presentations of patients with morbidity and mortality from bladder cancer.

\begin{tabular}{ccc}
\hline Parameters & Number of patients $(\mathrm{n}=234)$ & Percentage $(\%)$ \\
\hline Haematuria & 230 & 98.3 \\
LUTS & 230 & 98.3 \\
Uraemia & 161 & 68.8 \\
Childhood haematuria & 160 & 68.4 \\
Anaemia & 131 & 56 \\
Necroturia & 126 & 53.8 \\
Weight loss & 114 & 48.7 \\
Anorexia & 112 & 47.9 \\
Bladder mass & 109 & 46.6 \\
Urinary tract infection (UTI) & 75 & 32.1 \\
Hypertension & 8 & 3.4 \\
Open exploration & 3 & 1.3 \\
Rectovesical fistula & 3 & 1.3 \\
Vesico-cutaneous fistula/suprapubic cystostomy & 2 & 0.9 \\
\hline
\end{tabular}

Ultrasound
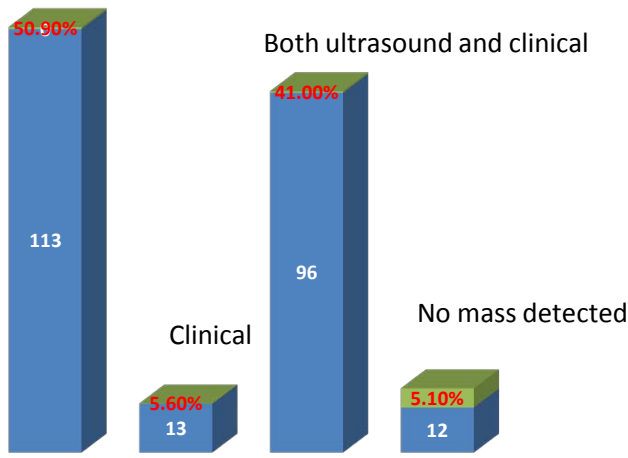

Figure 1. Detection of bladder mass by ultrasound and clinical examination.

Abdominopelvic ultrasound detected bladder mass and hydronephrosis in 115 patients (49.1\%) and bladder mass only in 104 patients (44.4\%). The patients with hydronephrosis are candidates for uraemia which is a common morbidity of bladder cancer in our environment.

The results of laboratory investigations revealed uraemia in $68.8 \%$, anaemia in $56 \%$, positive urine microscopy in $22.2 \%$, and urine cytology in $4.3 \%$. The commonest microorganism isolated in the urine was E coli (13.1\%). Other details of the laboratory findings are shown in Table 3.

Cystoscopy confirmed presence of bladder tumour in 72 patients and the histology revealed squamous cell carcinoma in 22 patients (9.4\%), transitional cell carcinoma in 19 patients $(8.1 \%)$, adenocarcinoma in 2 patients $(0.9 \%)$, rhabdomyosarcoma in 2 patients $(0.9 \%)$ and premalignant conditions in 27 patients (11.5\%).

All the patients were admitted and resuscitated with antibiotics, intravenous fluid with or without blood transfusion and haemodialysis. Patients (75) with uro- 
sepsis $(32.1 \%)$ received ceftriaxone sulbactam till the resolution of symptoms. Blood transfusion was given to 63 patients $(26.9 \%)$, haemodialysis was done in 23 patients $(9.8 \%)$, chemotherapy in 10 patients $(4.3 \%)$, radical cystectomy in 2 patients $(0.9 \%)$, transurethral resection of bladder tumour (TURBT) in 2 patients $(0.9 \%)$ and percutaneous nephrostomy in 1 patients $(0.4 \%)$. Those that did not respond to antibiotics were changed based on the microscopy results or recommendations of the medical microbiologist.

The rate of morbidity was $96.6 \%$ and mortality rate was $35.9 \%$. The commonest cause of morbidity and mortality from bladder cancer was uraemia as shown in Table 4.

There was positive association between uraemia and risk factors for bladder cancer $(\mathrm{p}=0.03)$, anaemia with uraemia $(\mathrm{p}=0.02)$ and bladder mass $(0.00)$, UTI and anorexia $(\mathrm{p}=0.02)$. The detailed analysis of the association of presentation with various morbidities is shown in Table 5.

There is a positive association of bladder mass with mortality $(\mathrm{p}=0.02)$. Other associations of the presentation with mortality are shown in Table 6.

The factors associated with the morbidity and mortality are late presentations, presence of multiple severe life-threatening complications like urosepsis, severe uraemia and financial constraints. Most of these patients (62\%) were also peasant farmers.

Most (122) of the patients (52.1\%) defaulted from follow up, 86 patients (36.8\%) died, 21 patients $(9.0 \%)$ left against medical advice, and 4 patients $(1.8 \%)$ were referred for further treatment

Table 3. Laboratory investigations findings.

\begin{tabular}{ccc}
\hline Laboratory Test & Number of patients & Percentage (\%) \\
\hline Urea & 161 & 68.8 \\
$>6.5 \mathrm{mg} \%$ & 44 & 18.8 \\
$<6.5 \mathrm{mg} \%$ & & \\
Creatinine & 150 & 64.1 \\
$>1.5 \mathrm{mg} \%$ & 56 & 23.9 \\
$\leq 1.5 \mathrm{mg} \%$ & & \\
Packed cell volume & 131 & 56.0 \\
$<30 \%$ & 33 & 14.1 \\
$>30 \%$ & & 22.2 \\
Urine microscopy & 52 & 23.5 \\
Growth present & 55 & \\
Growth absent & & 13.1 \\
Organism & 31 & 5.1 \\
E. coli & 12 & 2.1 \\
S. aureus & 5 & 1.3 \\
Streptococcus spp. & 3 & 0.4 \\
Klebsiella & 1 & 4.3 \\
Salmonella spp. & & 12.4 \\
Urine cytology & 10 & \\
Positive & 29 & \\
Negative & & \\
\hline & & \\
\hline
\end{tabular}


Table 4. Morbidity and mortality from bladder tumour.

\begin{tabular}{ccc}
\hline Parameter & Number of patients $(\mathrm{n}=234)$ & Percentage (\%) \\
\hline Morbidity & 226 & 96.6 \\
uraemia & 161 & 68.8 \\
Anaemia & 62 & 26.5 \\
UTI \pm urosepsis & 75 & 32.1 \\
Rectovesical fistula & 3 & 1.3 \\
Mortality & 84 & 35.9 \\
Uraemia & 52 & 22.2 \\
Urosepsis & 22 & 9.4 \\
Anaemia & 8 & 3.4 \\
Intestinal obstruction & 1 & 0.4 \\
Blood transfusion reaction & 1 & 0.4 \\
\hline
\end{tabular}

Table 5. Association of the presentations with morbidity.

\begin{tabular}{|c|c|c|c|}
\hline Presentation & Yes (\%) & No (\%) & $\mathrm{p}$ value (Fisher exact test) \\
\hline \multicolumn{4}{|c|}{ Uraemia } \\
\hline Haematuria & $159(78.3)$ & $44(21.7)$ & 1.00 \\
\hline LUTS & $160(78.8)$ & $43(21.2)$ & 1.00 \\
\hline Weight loss & $91(88.3)$ & $12(11.7)$ & 0.15 \\
\hline Anorexia & $90(89.1)$ & $11(10.9)$ & 0.11 \\
\hline Necroturia & $93(84.5)$ & $17(15.5)$ & 0.58 \\
\hline Bladder mass & $8(88.9)$ & $1(11.1)$ & 0.63 \\
\hline Risk factors* & $130(78.8)$ & $35(21.2)$ & 0.03 \\
\hline \multicolumn{4}{|c|}{ Anaemia } \\
\hline Haematuria & $129(79.6)$ & $33(20.4)$ & 1.0 \\
\hline LUTS & $130(79.8)$ & $33(20.2)$ & 1.0 \\
\hline Weight loss & $79(80.6)$ & $19(19.4)$ & 0.48 \\
\hline Anorexia & $80(82.5)$ & $17(17.5)$ & 0.45 \\
\hline Necroturia & $84(82.4)$ & $18(17.6)$ & 0.55 \\
\hline Bladder mass & $8(81.8)$ & $2(18.2)$ & 0.02 \\
\hline Uraemia & $109(88.6)$ & $14(11.4)$ & 0.001 \\
\hline UTI & $44(80)$ & $11(20)$ & 0.39 \\
\hline \multicolumn{4}{|c|}{ Urinary Tract Infection } \\
\hline Haematuria & $74(69.8)$ & $32(30.2)$ & 1.0 \\
\hline LUTS & $74(69.8)$ & $32(30.2)$ & 1.0 \\
\hline Weight loss & $32(62.7)$ & $19(37.3)$ & 0.62 \\
\hline Anorexia & $32(65.3)$ & $17(34.7)$ & 0.02 \\
\hline Necroturia & $35(60.3)$ & $23(39.7)$ & 0.56 \\
\hline Bladder mass & $1(50.0)$ & $1(50.0)$ & 0.38 \\
\hline Risk factors ${ }^{*}$ & $61(70.9)$ & $25(29.1)$ & 0.88 \\
\hline
\end{tabular}

${ }^{\star}$ Risk factors for bladder cancer (schistosomiasis and smoking).

Table 6. Association of presentation with mortality.

\begin{tabular}{cccc}
\hline Presentation & YES (\%) & No (\%) & p value (Fisher exact test) \\
\hline Haematuria & $84(36.5)$ & $146(63.5)$ & 0.13 \\
LUTS & $86(37.4)$ & $144(62.6)$ & 1.00 \\
Weight loss & $70(61.4)$ & $44(38.6)$ & 0.15 \\
Anorexia & $68(60.7)$ & $44(39.3)$ & 0.39 \\
Necroturia & $63(50.0)$ & $63(50.0)$ & 0.36 \\
Bladder mass & $55(57.3)$ & $44(42.7)$ & $\mathbf{0 . 0 0 1}$ \\
\hline
\end{tabular}




\section{Discussion}

Bladder cancer is the $10^{\text {th }}$ most common malignancy worldwide [1] and second most common malignancy in Sokoto Northwestern Nigeria [4]. The commonest histological type is squamous cell type which is invasive denovo [6]. Patients present with advanced disease with presence of necroturia, weight loss, anorexia, uraemia and recurrent urinary tract infection which may lead to mortality [3] [7]. Furthermore, the attendant morbidities in these patients can lead to prolonged hospital stay and increased financial cost of treatment on patients and caregiver who are already exhausted financially even prior to presentation.

The mean age of patients in this study of 48.4 years is lower than, but almost similar to 54.3 years reported by Rambau et al. [3] in Tanzania. The similarities may be accounted for by the endemicity of schistosomiasis which is a predominant predisposing factor of bladder cancer in the two studies. Most of the patients (91.5\%) were males, this is contrary to what was reported by Ramabu et al. [3]. This may be sociocultural or religious related, particularly in our environment where men are the predominant farmer who are supposed to fend for their wives who stay at home to take care of the domestic problems. Most of the patients in this study were farmers, a finding earlier reported by previous studies [5] [6].

The sixty-two percent of the farmers in this study engaged in subsistence farming. Hence, these are people with poor socio-economic status which correlates with short life expectancy and mortality from bladder cancer. Consequently, this leads to late presentation and coupled with the high prevalence of squamous cell carcinoma of the bladder and inability to afford or because of out-ofpocket payment for treatment, the treatment outcome of even those that may present relatively early may be poor [8].

The most common presentations were haematuria, LUTS, necroturia, anaemia, weight loss, anorexia and uraemia as reported by the previous studies [5] [6]. These are features of advanced disease and signal poor treatment outcomes. In addition, the patients have reduced quality of life and require multiple admissions for treatment of infections, blood transfusion and dialysis or nephrostomy. This has a tendency of exhausting the patient's income giving way for the possible mortality.

The most common causes of morbidity were anaemia, uraemia, urinary tract infection, urosepsis and rectovesical fistula, this is in agreement with the previous studies [3] [6] [7].

Uraemia was the commonest cause of mortality, which was higher than what was reported by the previous studies [6] [7]. The finding of anaemia and urosepsis as cause of mortality is similar to the previous studies [5] [6]. But the finding of mortality from intestinal obstruction and blood transfusion reaction is a rare finding in this study. The positive association between risk factors for bladder cancer and uraemia is in agreement with what is found in literature [2] [7]. Schistosomiasis predisposes the patients to bladder cancer and other pathologies such as recurrent infections and schistosomal obstruction which can predispose the 
patients to uraemia [3] [5] [6] [7]. The bladder cancer itself arises around the trigone, and with progression, it tends to occlude the ureteric orifices leading to uraemia. This is common with squamous cell carcinoma [3] [5]. This has not been established by the present study due to the small number of patients that underwent cystoscopy and biopsy. Most of the unconfirmed cases were unfit for cystoscopy biopsy and later left against medical advice due to inability to cope with the medical bills and unwillingness to spend money for a disease that is incurable. Similarly, the positive association of anaemia with uraemia and bladder mass is consistent with the previous studies [3] [6] [7]. Bladder mass is a feature of advanced disease which correlates with anaemia and uraemia. Anaemia may also be a feature of uraemia. In uraemic state, there is increased haemolysis of red blood cells, depression of bone marrow, decrease intake and absorption due to anorexia, bowel oedema and decrease production of erythropoietin by a failing kidney. A patient that presents with bladder mass is more likely to have a disease that has involved the trigone and ureteric orifices. The finding of association of the bladder mass with mortality is in agreement with the previous reports [2] [3] [6] [7]. These patients have advanced disease which can even be metastatic. The patients might not be fit for chemotherapy or may need renoprotective regimen when there is uraemia which the patients might not afford. The standard chemotherapy for bladder cancer is Methotrexate, Vincristine, Adriamycin and Cisplatin [MVAC] [2]. Cisplatin is substituted with carboplatin when there is renal impairment. Some patients were explored at the referral hospital with the presumption of prostatic enlargement or bladder stone which upstaged the bladder tumour leading to rapid mortality due to urosepsis from rectovesical or vesicocutaneous fistula. The mortality may also be due to metastatic disease. Other presentations such as weight loss, necroturia, rectovesical fistula did not show positive association. This may be explained by several factors among which include small numbers of such presentations such as rectovesical fistula as found in only 3 patients.

Generally, the factors that were associated with the morbidity and mortality included late presentations (bladder mass $\{0.01\}$, anorexia, $\mathrm{p}=0.002$ ), presence of multiple severe life-threatening complications like urosepsis, severe uraemia (0.001) and financial constraints. The significance of financial constraint was not assessed. Most of these patients are farmers who have already spent money in the peripheral hospital before referral to our hospital and with the out-of-pocket payment, as no insurance cover for the average citizen that is not in the federal government service. This is in keeping with previous reports of the health system, challenges and management of patients in 3rd world countries [8].

The limitations of this study include retrospective nature of the study, data retrieval, inability to do cystoscopy for many patients because of their haemodynamic instability, the reliance on history of haematuria and necroturia, ultrasound finding of bladder mass, and urine cytology for diagnosis. The bladder tumour biopsy histology result of some of the patients with extensive necroturia, 
yielded necrosis and benign finding. Some patients did not consent to repeat biopsy and defaulted subsequently. The significance of financial constraint should have been assessed.

We propose a prospective study that is going to be informative in terms of histology and factors that affect morbidity and mortality in these patients.

\section{Conclusion}

Bladder tumours are associated with high morbidity and or mortality in our environment. The morbidity and mortality are due to anaemia, rectovesical fistula and urosepsis. It poses great diagnostic and therapeutic dilemma to the urologist, patients and their relatives. There is positive association between bladder mass and anorexia with anaemia, uraemia, urinary tract infection and mortality from bladder cancer.

\section{Conflicts of Interest}

The authors declare no conflicts of interest regarding the publication of this paper.

\section{References}

[1] Richters, A., Aben, K.K.H. and Kiemeney, A.L.M. (2020) The Global Burden of Urinary Bladder Cancer: An Update. World Journal of Urology, 38, 1895-1904. https://doi.org/10.1007/s00345-019-02984-4

[2] Guzzo, T.J. and Vaughn, D.J. (2016) Management of Invasive and Metastatic Bladder Cancer. In: Wein, A.J., Partin, A.W., Peters, C.A., Eds., Campbell-Walsh's Urology, 11th Edition, Elsevier Sunders, Philadelphia, 6412-6442.

[3] Rambau, P.F., Chalya, P.L. and Jackson, K. (2013) Schistosomiasis and Urinary Bladder Cancer in North Western Tanzania: A Retrospective Review of 185 Patients. Infect Agent Cancer, 8, 19. https://doi.org/10.1186/1750-9378-8-19

[4] Sahabi, S.M. and Abdullahi, K. (2017) Epidemiological Survey of Malignant Neoplasms in Sokoto, Nigeria. World Journal of Research and Review, 4, 10-15. https://media.neliti.com/media/publications/262828-epidemiological-survey-of-mal ignant-neop-7a31ecf1.pdf

[5] Mungadi, I.A. and Malami, S.A. (2007) Urinary Bladder Cancer and Schistosomiasis in North-Western Nigeria. West African Journal of Medicine, 26, 226-229. https://doi.org/10.4314/wajm.v26i3.28315

[6] Muhammad, A.S., Mungadi, I.A., Ndodu, E.D. and Kalayi, G.D. (2018) Performance of Urinary Survivin as a Non-Invasive Molecular Marker of Bladder Carcinoma in a Schistosomiasis Endemic area. Ghana Medical Journal, 52, 74-78. https://doi.org/10.4314/gmj.v52i2.2

[7] Muhammad, A.S., Abdulwahab-Ahmed, A., Agwu, P.N., Abdullahi, K. and Mungadi, I.A. (2017) Management of Obstructive Nephropathy in a Tertiary Hospital in North West Nigeria: A Five-Year Review. East and Central African Journal of Surgery, 22, 42-49. https://doi.org/10.4314/ecajs.v22i3.6

[8] Mahdavifar, N., Ghoncheh, M., Pakzad, R., Momenimovahed, Z. and Salehiniya, H. (2016) Epidemiology, Incidence and Mortality of Bladder Cancer and Their Relationship with the Development Index in the World. Asian Pacific Journal of Cancer Prevention, 17, 5-8. https://doi.org/10.7314/APJCP.2016.17.1.381 